\title{
The use of pentoxifylline in male reproduction abnormalities
}

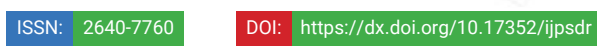

\section{Aamir Jalal Al-Mosawi*}

Received: 30 July, 2021

Accepted: 09 August, 2021

Published: 10 August, 2021

*Corresponding author: Aamir Jalal Al-Mosawi, Advisor Doctor, National Training and Development Center of the Iraqi Ministry of Health, Baghdad, Iraq,

E-mail:almosawiaj@yahoo.com

Keywords: Pentoxifylline; Male; Reproductive abnormalities; Therapeutic effects

https://www.peertechzpublications.com

Advisor Doctor, National Training and Development Center of the Iraqi Ministry of Health, Baghdad,

Check for updates

Iraq

\begin{abstract}
Pentoxifylline a derivative of methylxanthine and nonspecific inhibitor of the phosphodiesterase with vasodilatory properties and rheological properties on blood that made it useful in the treatment of intermittent claudication. Pentoxifylline also has an immunomodulatory effect which inhibits inflammatory cytokines including tumor necrosis factor-alpha. The aim of this paper is to review the uses of pentoxifylline in male reproduction abnormalities.
\end{abstract}

Allenby and colleagues (1991) reported three impotent patients with claudication of the lower limbs whom were treated with pentoxifylline, and spontaneously reported improved sexual function [1].

Korenman and Viosca (1993) reported a controlled study which included males with mild to moderate penile vascular insufficiency causing impotence whom were treated with pentoxifylline 400mg twice daily for 12 weeks. Pentoxifylline treatment regularly increased the penile-brachial pressure index frequently into the normal range, in comparison with patients who received placebo. In 9 of 12 patients, pentoxifylline treatment was associated with reestablishment of coital function [2].

Peşkircioğlu (1996) reported a study which included 36 patients with borderline arterial disease diagnosed with penile duplex ultrasonography. Twenty patients (Aged 40-66 years, mean age 54 years) were treated with oral $400 \mathrm{mg}$ three times daily for 2 months. Sixteen patients (34-65, mean age 54 years) received a placebo. Pentoxifylline treatment increased peak systolic velocities on penile duplex ultrasonography in 12 of the 20 , and the mean change in peak systolic velocities caused by pentoxifylline treatment $(6.25 \mathrm{~cm} / \mathrm{s})$ was considerably higher than the observed in the control patients $(0.38 \mathrm{~cm} / \mathrm{s})$. Seven patients treated by pentoxifylline had successful coitus. Treatment was not associated with side effects [3].
Ozdal, et al. (2008) reported a study which included 68 patients with various degrees and types of vasculogenic erectile dysfunction who were treated initially with oral sildenafil (minimum two 50-mg tablets/week), 60 minutes before sexual intercourse for four weeks. Thereafter, pentoxifylline $400 \mathrm{mg}$ three times daily was to the treatment for the next four weeks period. The mean international index of erectile function score was higher after sildenafil treatment than before treatment score. The international index of erection function score of the patients was higher after the combination treatment compared to pre-treatment score. The increase in international index of erectile function score was 5.62+/-2.08 with sildenafil treatment, but the score increased $9.51+/-3.77$ with the combination therapy. $(\mathrm{P}<0.001)$. Ozdal et al suggested the use of sildenafil citrate and pentoxifylline combined therapy in the treatment of patients with vasculogenic erectile dysfunction [4].

Kumar, et al. (2015) reported a study which included 237 patients having erectile dysfunction whom were treated with tadalafil or tadalafil + pentoxifylline for 8 weeks. $78.6 \%$ of the patients treated with tadalafil reported improvement. $86.6 \%$ of the patients treated with tadalafil + pentoxifylline reported improvement. There was no significant difference in between the two groups with regards to occurrence of side effects [5].

Aparicio and colleagues (1980) reported a study which included 15 infertile men (aged 22 to 44 years) with 
normogonadotropic asthenozoospermia who were treated with pentoxifylline $1200 \mathrm{mg}$ daily for at least four months. Treatment was associated with marked improvement of the percentages of forwardly progressive spermatozoa and of live and motile spermatozoa. Five of the patients experienced normalization of semen, and seven experienced improvement in comparison to pre-treatment values. Pregnancy was achieved in two patients [6].

Schill (1980) reported a study which included 25 males with idiopathic asthenozoospermia and forty males with idiopathic normogonadotropic oligozoospermia who received oral pentoxifylline $1200 \mathrm{mg}$ daily for three months. Treatment was associated with considerable increase of progressive sperm movement in patients with asthenozoospermia, and the conception rate was $37 \%$. Patients with normogonadotropic experienced only a little temporary increase of the ejaculate volume and the level of seminal plasma fructose, and the conception rate $17 \%$. Schill suggested that the mechanism of action of pentoxifylline involves improving the microcirculation of the epididymis and the accessory sexual glands resulting in improved epididymal sperm maturation [7].

Marrama, et al. (1985) reported a study which included 22 males (mean age 28.4 years) who had idiopathic oligoasthenozoospermia, whom were treated oral pentoxifylline $1200 \mathrm{mg}$ daily for six months. Treatment was associated with marked increase in sperm count and motility. Sperm count increased a 1.5-fold ( $\mathrm{p}$ less than 0.01) at the third month of treatment, increased a 2.0-fold ( $\mathrm{p}$ less than 0.001 ) at the sixth month of treatment. Sperm movement increased by 1.8 -fold ( $p$ less than 0.001) at the third month of treatment, and was higher by 2.8 -fold ( $\mathrm{p}$ less than 0.001 ) at the sixth month of treatment. After treatment, fructose level in seminal fluid was considerably elevated ( $p$ less than 0.001) than before. Sperm ATP level was markedly lower after treatment ( $p$ less than 0.05). Marrama et al suggested that pentoxifylline may have a beneficial effect on the metabolism of the cAMP, and can be used to treat idiopathic oligo-asthenozoospermia [8].

Merino, et al. (1997) reported a controlled study which included 47 males with normogonadotropic men with idiopathic asthenozoospermic. Twenty-five patients were treated with pentoxifylline $1200 \mathrm{mg}$ daily during 6 months, and 22 patients receive placebo. Pentoxifylline treatment increased sperm motility from $25.5(21.0-30.0)$ to 35.5 (31.5-39.0) (p $<.00001)$, and to $42.0(38.0-46.0)(\mathrm{p}<.00001)$ after 3 and 6 months respectively. Changes in the control patients were less significant. Additionally, pentoxifylline increased progressive motility from $2.5(0.0-6.0)$ to $12.0(6.0-19.5)(\mathrm{p}<.001)$ at 3 months, and to $22.5(17.0-26.0)$ at 6 months ( $<$.00001) [9].

Oliva, et al. (2009) reported the treatment of thirtysix males with varicocele-associated infertility with oral pentoxifylline with zinc and folic acid for 12 weeks. Treatment was associated with marked increase in the proportion of morphologically normal sperm cells [10].

Safarinejad (2011) reported a double-blind study which included 254 infertile males. 127 patients were treated with pentoxifylline $400 \mathrm{mg}$ twice daily for six months, 127 received placebo. Treatment was associated with marked increase in sperm count, sperm motility, and sperm with normal morphology, while the controlled patients experience a subtle decrease in these parameters [11].

Azgomi, et al. (2018) reported a study which include 100 males with infertility of unknown cause whom were treated with either pentoxifylline $800 \mathrm{mg} /$ daily or Withania somnifera herbal capsules (5g/daily) for 90 days. Pentoxifylline elevated mean semen volume $(16.46 \%)$, progressive movement $(25.97 \%)$ and its use was associated with a sperm morphology (13.28\%). Withania somnifera also increased mean sperm count $(12.5 \%)$ and progressive motility $(21.42 \%)$ and improved sperm morphology (25.56\%) [12].

\section{Conclusion}

The available research evidence suggests that the addition of pentoxifylline to the traditional treatment of erectile dysfunction can be helpful, it also beneficial in the treatment of oligo-asthenozoospermia, possibly through stimulation of sperm's movement through elevating the levels of intracellular cAMP.

\section{References}

1. Allenby KS, Burris JF, Mroczek WJ (1991) Pentoxifylline in the treatment of vascular impotence--case reports. Angiology 42: 418-420. Link: https://bit.ly/3s6ISLB

2. Korenman SG, Viosca SP (1993) Treatment of vasculogenic sexual dysfunction with pentoxifylline. J Am Geriatr Soc 41: 363-366. Link: https://bit.ly/3CyMNpA

3. Peşkircioğlu L, Karabulut A, Deniz E, Germiyanoğlu C, Erol D (1996) The role of pentoxifylline in the treatment of erectile dysfunction due to borderline arterial insufficiency. Br J Urol 77: 563-565. Link: https://bit.ly/3fFQNdZ

4. Ozdal OL, Ozden C, Gokkaya S, Urgancioglu G, Aktas BK, et al. (2008) The effect of sildenafil citrate and pentoxifylline combined treatment in the management of erectile dysfunction. Int Urol Nephrol 40: 133-136. Link: https://bit.ly/3IIIwuL

5. Kumar S, Roat R, Agrawal S, Jayant K, Mavuduru RS, et al. (2015) Combination therapy of tadalafil and pentoxifylline in severe erectile dysfunction: A Prospective randomized trial. Pol Przegl Chir 87: 377-383. Link: https://bit.ly/3jSp7UD

6. Aparicio NJ, Schwarzstein L, de Turner EA (1980) Pentoxifylline (BL 191) by oral administration in the treatment of asthenozoospermia. Andrologia 12 228-231. Link: https://bit.ly/3Cxcd6U

7. Schill WB (1982) Therapy of idiopathic astheno- and oligozoospermia with pentoxifylline. Fortschr Med 100: 696-700. Link: https://bit.ly/3IGV1pz

8. Marrama P, Baraghini GF, Carani C, Celani MF, Giovenco P, et al. (1985) Further studies on the effects of pentoxifylline on sperm count and sperm motility in patients with idiopathic oligo-asthenozoospermia. Andrologia 17: 612-616. Link: https://bit.ly/3iwVvg3

9. Merino G, Martínez Chéquer JC, Barahona E, Bermúdez JA, Morán C, et al. (1997) Effects of pentoxifylline on sperm motility in normogonadotropic asthenozoospermic men. Arch Androl 39: 65-69. Link: https://bit.ly/3s33zlf

10. Oliva A, Dotta A, Multigner L (2009) Pentoxifylline and antioxidants improve sperm quality in male patients with varicocele. Fertil Steril 91: 1536-1539. Link: https://bit.ly/3AjSipS 
11. Safarinejad MR (2011) Effect of pentoxifylline on semen parameters, reproductive hormones, and seminal plasma antioxidant capacity in men with idiopathic infertility: a randomized double-blind placebo-controlled study. Int Urol Nephrol 43: 315-328. Link: https://bit.ly/3iwgsYk
12. Azgomi R, Nazemiyeh $H$, Sadeghi Bazargani H, Fazljou SMB, Nejatbakhsh $F$, et al. (2018) Comparative evaluation of the effects of Withania somnifera with pentoxifylline on the sperm parameters in idiopathic male infertility: A triple-blind randomised clinical trial. Andrologia 50: e13041. Link: https://bit.ly/3jl35DY

\section{Discover a bigger Impact and Visibility of your article publication with}

\section{Peertechz Publications}

\section{Highlights}

* Signatory publisher of ORCID

* Signatory Publisher of DORA (San Francisco Declaration on Research Assessment)

* Articles archived in worlds' renowned service providers such as Portico, CNKI, AGRIS, TDNet, Base (Bielefeld University Library), CrossRef, Scilit, J-Gate etc.

* Journals indexed in ICMJE, SHERPA/ROMEO, Google Scholar etc.

- OAI-PMH (Open Archives Initiative Protocol for Metadata Harvesting)

* Dedicated Editorial Board for every journal

* Accurate and rapid peer-review process

- Increased citations of published articles through promotions

* Reduced timeline for article publication

Submit your articles and experience a new surge in publication services (https://www.peertechz.com/submission).

Peertechz journals wishes everlasting success in your every endeavours.

Copyright: $\odot 2021$ Al-Mosawi AJ. This is an open-access article distributed under the terms of the Creative Commons Attribution License, which permits unrestricted use distribution, and reproduction in any medium, provided the original author and source are credited. 